\title{
EDUCAÇÃO E A EMANCIPAÇÃO SOCIAL NA TRAJETÓRIA DE VIDA DOS SUJEITOS DA EJA
}

Adriana de Mello Amorim Novais Silva ${ }^{1}$

Nereida Maria Santos Mafra de Benedictis ${ }^{2}$

\section{RESUMO}

Este estudo versa sobre o papel da educação escolarizada para a emancipação social na perspectiva dos sujeitos da Educação de Jovens e Adultos (EJA). Com o intuito de compreender a relação entre educação escolarizada e emancipação social, utilizou-se da análise de mosaicos elaborados pelos sujeitos da pesquisa. Portanto, foram usados como referencial teórico os estudos sobre trajetória de vida, relacionando os conceitos de habitus e campos de Bourdieu (1989, 2007, 2011) e emancipação social na perspectiva de Freire (1980, 2006, 2013) e Adorno (1995). Os dados coletados pertencem às pesquisas realizadas durante o mestrado (de 2018 a 2020), sobretudo, com o mosaico. Por meio dessa atividade, foram analisadas as seguintes categorias: desenvolvimento da pessoa humana, protagonismo, participação crítica na sociedade e no mundo do trabalho. Percebeu-se a importância da escolarização para a vida dos sujeitos da EJA, nos campos familiar, laboral e social, em níveis e necessidades diferentes.

Palavras-chave: Educação Escolarizada. Emancipação Social. EJA.

\footnotetext{
${ }^{1}$ Mestre em Educação. Professora efetiva do Estado da Bahia no CEAP. Membro do grupo de pesquisa Núcleo de Análise em Memória Social e Espaço - NUAMSE e do grupo de pesquisa no Ensino de Pesquisa no Ensino da Geografia - GRUPEG da UESB. ORCID: http://orcid.org/0000-0002-6025-4737. E-mail: dica_novais@hotmail.com.

2 Doutora em Memória, Linguagem e Sociedade. Mestrado em Ciências Sociais. Professora Adjunta do Departamento de Geografia da Universidade Estadual do Sudoeste da Bahia e do Programa de Pós Graduação em Educação da UESB. Líder do NUAMSE - Grupo de Pesquisa Núcleo de Análise em Memória Social e Espaço e membro pesquisadora do GRUPEG. ORCID: http://orcid.org/0000-0001-9257-3487. E-mail:
} nereidamafrabenedictis@gmail.com. 


\section{EDUCATION AND SOCIAL EMANCIPATION IN THE LIFE STORY OF EJA SUBJECTS}

\section{ABSTRACT}

This study presents the role of school education for social emancipation from the perspective of the subjects of Youth and Adult Education (EJA). In order to understand the relationship between school education and social emancipation, we analysed the mosaics that were elaborated by the research subjects. For this understanding, the studies of the life trajectory categories were used as a theoretical framework, relating the concepts of habitus and fields, with Bourdieu (1989, 2007 and 2011) and social emancipation from the perspective of Freire (1980, 2006 and 2013) and we bring some considerations from Adorno (1995). He collected data belong to the researches carried out during the master degree (2018-2020), especially with the mosaic. By means of this activity, the following categories were analyzed: human development, protagonism, critical participation in society and in the working world. The importance of schooling for the lives of EJA subjects was perceived in the family, work and social fields at different levels and needs.

Keywords: School Education. Social Emancipation. EJA.

\section{EDUCACIÓN Y EMANCIPACIÓN SOCIAL EN LA TRAYECTORIA DE VIDA DE LOS INDIVIDUOS EJA}

\section{RESUMEN}

Este estudio presenta el papel de la educación escolar para la emancipación social desde la perspectiva de los individuos de Educación de Jóvenes y Adultos (EJA). Para comprender la relación entre educación escolar y emancipación social se utilizó el análisis de mosaicos elaborados por los sujetos de investigación. Para esta comprensión, se utilizaron como marco teórico los estudios de las categorías de trayectorias de vida, relacionando los conceptos de 
habitus y campos, con Bourdieu (1989, 2007 y 2011) y la emancipación social desde la perspectiva de Freire (1980, 2006 y 2013). y traemos algunas consideraciones de Adorno (1995). Los datos recogidos pertenecen a investigaciones realizadas durante el máster (2018 a 2020), especialmente con el mosaico. A través de esta actividad se analizaron las siguientes categorías: desarrollo humano, protagonismo, participación crítica en la sociedad y en el mundo del trabajo. La importancia de la escolarización para la vida de los sujetos de EJA se percibió en el ámbito familiar, laboral y social en diferentes niveles y necesidades.

Palabras clave: Educación escolar. Emancipación social. EJA.

\section{INTRODUÇÃO}

O presente trabalho busca compreender a relação entre educação escolarizada e emancipação social para os sujeitos da EJA. Os dados para análise fazem parte dos estudos desenvolvidos para a construção da dissertação do Mestrado do Programa de PósGraduação em Educação (PPGED) da Universidade Estadual do Sudoeste da Bahia (UESB), intitulada "Trajetória de Vida dos sujeitos da EJA e o papel dos saberes geográficos para a emancipação social" (2020). Para compor o aporte teórico do estudo, foi necessário apresentar a concepção de trajetória de vida e da emancipação social, analisar a percepção dos sujeitos da EJA com o processo de escolarização e compreender a relação entre educação escolarizada e emancipação social para os sujeitos da EJA.

$O$ interesse pela temática surgiu por meio de conversas com os sujeitos participantes da pesquisa, 11 sujeitos educandos do turno noturno da turma do $3^{\circ}$ Tempo Formativo Eixo VI, "Humanas", de um colégio estadual da cidade de Vitória da Conquista- BA. Nos diálogos, os sujeitos apresentaram a importância de estar na escola e terminar o Ensino Médio, para a família e para o mercado de trabalho.

O caminho metodológico perpassou pela pesquisa teórica sobre a trajetória de vida com Bourdieu (2011) e sobre a emancipação social na perspectiva de Freire (1980) e Adorno (1995). Em Arroyo (2017), buscaram-se as nuances dos sujeitos jovens, adultos e idosos 
participantes das turmas da EJA, noturno. Após a fundamentação teórica, buscou-se a percepção dos 11 sujeitos participantes das turmas da EJA, noturno, por meio dos mosaicos. Para tornar a atividade mais didática, realizamos a apresentação da atividade por meio de slides, abordando sobre o que é um mosaico e sua função. Em seguida, foi apresentado o tema a ser exposto no mosaico: "A educação na trajetória de vida dos sujeitos da EJA". Após essa etapa, cada sujeito recebeu uma folha $\mathrm{A} 3$, folhas coloridas, revistas e outros materiais para recortar, colar e pintar de acordo com sua imaginação. Assim, os mosaicos foram elaborados pelos sujeitos da pesquisa, a fim de explanar sobre a sua vida no dia a dia no formato de imagens. Com os dados coletados da atividade dialógica, analisamos a relação dos saberes escolares e a emancipação na vida dos sujeitos matriculados na modalidade da EJA do Colégio Estadual Adelmário Pinheiro (CEAP).

Com os mosaicos, buscaram-se os benefícios que a educação escolar pode trazer à vida de cada um. Para analisarmos os mosaicos, observamos o título apresentado pelos sujeitos; depois, foi realizada a descrição das imagens. Com essas considerações, utilizamos as categorias de análise: desenvolvimento da pessoa humana, protagonismo, participação crítica na sociedade e mundo do trabalho, para buscarmos compreender a relação entre a educação escolarizada e a emancipação social.

\section{EDUCAÇÃO ESCOLAR E A TRAJETÓRIA DE VIDA DOS SUJEITOS DA EJA}

Os sujeitos da EJA fazem parte de grupos sociais com a família, com os colegas no trabalho, na escola, na igreja, com os amigos, e esta realidade possibilita a construção e reconstrução de suas vivências e experiências nas relações sociais nos espaços e no tempo, construindo e reconstruindo suas aprendizagens individuais e coletivas. No espaço/tempo familiar e laboral, Arroyo (2017, p. 69) traz a complexidade da formação desse sujeito, que

[...] vem do trabalho para a educação não carregando apenas os valores, saberes, identidades 
de suas vivências pessoais de lutas por trabalho. Desde crianças são herdeiros dos valores, da consciência, das identidades da classe trabalhadora.

Das famílias trabalhadoras. [...] Há um traço marcante nas identidades coletivas dos jovensadultos que lutam pela educação: sabem-se trabalhadores e trabalhadoras.

Na trajetória de vida do sujeito da EJA, este traz em seu habitus sua formação social, voltada para a necessidade de adquirir um emprego. Na perspectiva dos tempos de sobrevivência (ARROYO, 2017), prioriza-se o emprego para a manutenção econômica pessoal e da família. O tempo de labor está relacionado a uma vaga no mercado de trabalho, a educação escolarizada, nesse sentido, deixa de ser prioridade.

A trajetória de vida desses sujeitos, para Arroyo (2017, p. 29), "[...] pesa com pesado peso sobre suas trajetórias de vida. Não carregam um passado rosado". Assim, conhecer a trajetória de vida do sujeito/estudante da EJA possibilita construir uma proposta pedagógica que considere o sujeito como participante ativo do meio em que vive, com necessidade de sobrevivência e da conciliação do emprego com o estudo. Esses sujeitos precisaram parar os estudos por motivos pessoais, familiares e laborais e, hoje, retornam ao colégio, para uma educação escolarizada, por necessidade de qualificação profissional.

É muito comum que os sujeitos da EJA, modalidade que visa a atender sujeitos em idade de trabalho, busquem por certificação para garantir o emprego ou galgar um emprego e um futuro melhor. Segundo Arroyo (2017, p. 48), "As lutas das famílias trabalhadoras por escola e por educação para seus filhos têm sido inseparáveis de suas lutas por trabalho, por digno viver". Portanto, a relação entre estudo e trabalho perpassa as relações sociais das famílias de trabalhadores, sempre priorizando o econômico. Contudo, há uma conscientização dos sujeitos/responsáveis pelas famílias acerca da importância da educação para o mercado de trabalho no presente e para o futuro. 


\section{TRAJETÓRIA DE VIDA E A EMANCIPAÇÃO SOCIAL NA PERSPECTIVA FREIREANA}

A trajetória de vida é o resultado das ações e movimentos do sujeito, que é moldado em suas relações culturais, materiais e simbólicas nos espaços em que convive; dito de outro modo, é na realidade social que se faz o sujeito. Para a compreensão desse movimento dialético, trouxemos o conceito de trajetória de vida proposto por Pierre Bourdieu (1989, 2007 e 2011), com a relação entre habitus e campos. Em relação à emancipação social, usamos Freire e Shor (2001) e Adorno (1995).

Antes de iniciarmos as discussões sobre trajetória de vida, precisa-se entender que, para Freire (1980), "[...] no momento, porém em que se comece a autêntica luta para criar a situação que nascerá a superação da velha, já se está lutando pelo Ser Mais". A partir do momento em que o sujeito busca por mudança em sua vida, na sua formação escolar, com a construção de saberes, no desenvolvimento pessoal e com o outro, que possam vir a auxiliá-los em suas relações sociais, está se fazendo Ser Mais, saindo da inércia da existência para a construção do habitus que busca por libertação.

Bourdieu (2011) concebe a trajetória de vida articulando os conceitos de campos e habitus. Para o autor, a trajetória de vida é linear, cronologicamente ordenada por eventos sucessivos, e ocorre nos espaços de convivência do sujeito, ou seja, os eventos sucedem em posições que foram sucessivamente ocupadas pelos sujeitos no campo. Portanto,

[...] à construção da noção de trajetória como uma série de posições sucessivamente ocupadas por um mesmo agente (ou um mesmo grupo), em um espaço ele próprio em devir e submetido a transformações incessantes. Tentar compreender uma vida como uma série única $e$, por si só, suficiente de acontecimentos sucessivos, sem outra ligação que a vinculação a um "sujeito" cuja única constância é a do nome próprio, é quase tão absurdo quanto tentar explicar um trajeto no metrô sem levar em conta a estrutura da rede, isto é, a 
matriz das relações objetivas entre as diversas estações (grifos nossos) (BOURDIEU, 2011, p. 81). (grifos nossos)

O "nome próprio" é um elemento social importante para identificação do sujeito no sistema social, não podemos menosprezálo, mas, como Bourdieu (2011) nos apresenta, há todo um habitus em cada um, "[...] age como suporte de um conjunto de atributos e de atribuições que permitem sua intervenção como agente eficiente nos diferentes campos. [...]" (p. 82). Na realização e análise da pesquisa exploratória para construção do perfil dos educandos da EJA de uma escola estadual, em 2018, mesmo não sendo necessária a identificação, percebemos que todos a fizeram por motivos variados ou imaginando que o questionário estivesse relacionado a uma vaga de emprego ou para garantir a sua informação. Esses são os sujeitos de direitos a serem reconhecidos por seus caminhos, vivências e experiências, por suas trajetórias de vida.

A contribuição que Bourdieu trouxe com o conceito de trajetória de vida é de suma importância para o entendimento dos diversos sujeitos da nossa sociedade e, em especial, para os sujeitos das turmas da EJA. Cada um participa do seu dia a dia de acordo com a posição social, econômica e cultural, e essas relações ocorrem de formas diferentes de acordo com o espaço social em que está inserido, na família, na escola, no trabalho e em outros "campos" (BOURDIEU, 1989). Nessas vivências, o sujeito modela o seu eu, que Bourdieu (2007) conceituou como habitus; essa formação e transformação social não se devem somente ao ser ou somente ao ambiente ao seu redor, mas são traçadas por meio da inter-relação entre estes.

O sujeito possui um habitus marcado, construído pelas relações sociais com o outro e com os espaços simbólicos, escola, trabalho, família e outros. Nessas inter-relações, (re)constrói-se o sujeito, que poderá agir como opressor ou oprimido, "E aí está a grande tarefa humanista e histórica dos oprimidos - libertar-se a si e aos opressores" (FREIRE, 1980, p. 31). O processo de libertação está relacionado à percepção de ser um agente social, necessário para a superação das contradições e a busca por uma relação humanizada. 
No momento em que sujeitos são proibidos de Ser Mais, há uma violência simbólica e real na construção do habitus.

O estudo sobre as trajetórias de vida dos sujeitos da EJA é um importante recurso para conhecer quem são e como estes utilizam os saberes escolares nas suas relações sociais. No entanto, devemos considerar que a trajetória de vida está diretamente ligada às condições concretas dos campos de vivência dos sujeitos.

No livro de Bourdieu (2011), A Economia das Trocas Simbólicas, percebemos a importância do conceito habitus para o estudo da trajetória de vida dos sujeitos. A formação do habitus ocorre desde as primeiras relações sociais, no convívio familiar, com amigos, na escola e/ou no trabalho numa relação de formação, transformação e socialização dos sujeitos. Assim,

Os 'sujeitos' são, de fato, agentes que atuam e que sabem, dotados de um senso prático, de um sistema adquirido de preferências, de princípios de visão e de divisão (o que comumente chamamos de gosto), de estruturas cognitivas duradouras (que são essencialmente produtos da incorporação de estruturas objetivas) e de esquemas de ação que orientam a percepção da situação e a resposta adequada. O habitus é essa espécie de senso prático [...] (BOURDIEU, 2011, p. 42, grifos nossos).

Cada sujeito passa por experiências diárias que o formam e transformam continuamente; portanto, as relações sociais, progressivamente, são inscritas na mente e no corpo de cada pessoa e a fazem ser como é, moldando o habitus. Nessa perspectiva, Miceli (2007, p. XLII) entende que:

[...] o habitus seria um conjunto de esquemas implantados desde a primeira educação familiar, e constantemente repostos e reatualizados ao longo da trajetória social restante, que demarcam os limites à consciência possível de ser mobilizada pelos grupos e/ou classes, sendo assim responsáveis, em última instância, pelo campo de sentido em que operam as relações de força. 
O conceito de habitus está ligado à corporificação das disposições socialmente adquiridas, ou seja, as vivências escritas no corpo do indivíduo biológico, aquele que pode levar o indivíduo a viver de acordo com as suas individualidades essenciais, ou seja, suas subjetividades. Tais caminhos escolhidos ou impostos pelas vivências vão impactar nas próximas trajetórias. No caso dos educandos matriculados na EJA, encontramos sujeitos que precisaram escolher entre estudar e outras vivências e experiências prioritárias naquele dado momento e podemos conjecturar que necessitaram deixar de estudar no tempo formal a fim de trabalharem para o seu sustento e/ou o da família. E, no decorrer das suas trajetórias de vida, com as escolhas pessoais, suas capacitações ou restrições foram marcando as relações com os diversos espaços sociais.

Ainda sobre a importância de se conhecer a trajetória de vida dos sujeitos da EJA, podemos exemplificá-la com o processo de ensino aprendizagem que ocorre no contexto escolar. No processo de escolarização, o professor ou a professora não avalia somente o que é ensinado em sala de aula, há toda uma gama de habilidades e competências que são solicitadas aos educandos que derivam de outros campos. Bourdieu (1989) apresenta que, nesse processo, enfatizam-se as diferenças, e não os saberes adquiridos com o processo de ensino aprendizagem que ocorre no ambiente escolar. Nesse sentido, foi salutar pensar no sujeito do nosso objeto de estudo e conhecer os educandos matriculados nas turmas da modalidade de educação para jovens, adultos e idosos, que já passaram por diversas vivências e poderão contribuir com as aulas, trazendo suas experiências e contextualizando os conteúdos que foram por eles apreendidos.

O habitus está associado à posição que o sujeito ocupa em cada espaço/campo; este pode ser o campo familiar, o artístico, o religioso, o laboral, o político, o científico, o acadêmico e outros de que participa. Para Bourdieu (1989), os campos são espaços simbólicos que possuem relações objetivas, históricas e atuais nos quais ocorrem disputas de poder entre os "agentes" por meio dos diferentes tipos de capital. Esta pesquisa busca compreender o capital cultural adquirido no ambiente escolar e como este interfere nos diversos campos dos sujeitos da EJA. Nessa perspectiva, 
[...] o campo social como um espaço multidimensional de posições tal que qualquer posição actual pode ser definida em função de um sistema multidimensional de coordenadas cujos valores correspondem aos valores das diferentes variáveis pertinentes: os agentes distribuem-se assim nele, na primeira dimensão, segundo o volume global do capital que possuem e, na segunda dimensão, segundo a composição do seu capital - quer dizer, segundo o peso relativo das diferentes espécies no conjunto das suas posses (BOURDIEU, 1989, p. 135).

Dos vários campos sugeridos por Bourdieu (1989), na sua multidimensionalidade, aproximamo-nos de alguns que fazem parte da vida dos sujeitos da EJA do Ensino Médio, quais sejam, o campo familiar, laboral, escolar - lembrando que outros campos, como o religioso e os espaços de lazer, estão presentes em suas vidas.

O conhecimento das trajetórias de vida dos sujeitos da EJA, seus habitus e os campos onde se relacionam são uma ferramenta importante para o processo de escolarização, para a elaboração dos planos de curso e de aula a fim de que haja diálogo entre o que é proposto e a necessidade do educando. As necessidades culturais são produtos da sociedade, e a educação escolar é uma forma de perpetuar e garantir o que está posto na sociedade. Bourdieu (2007) utiliza o termo capital cultural para explicar como a cultura ${ }^{3}$ em uma sociedade dividida em classes transforma-se em instrumento de dominação, o qual as classes dominantes utilizam para acentuar as diferenças. As ideias de Bourdieu podem analisar o sistema escolar:

A escola não cumpre apenas a função de consagrar a "distinção" - no sentido duplo do termo - das classes cultivadas. A cultura que ela transmite separa os que a recebem do restante da sociedade

\footnotetext{
${ }^{3}$ Cultura: "[...] esse termo tem dois significados básicos. No primeiro e mais antigo, significa a formação do homem, sua melhoria e seu refinamento. [...] No segundo significado, indica o produto dessa formação, ou seja, o conjunto dos modos de viver e de pensar cultivados, civilizados, polidos, que também costumam ser indicados pelo nome de civilização. [...]" (ABBAGNANO, 2007, p. 225).
} 
mediante um conjunto de diferenças sistemáticas: aqueles que possuem como "cultura" (no sentido dos etnólogos) a cultura erudita veiculada pela escola dispõem de um sistema de categorias de percepção, de linguagem, de pensamento e de apreciação, que os distingue daqueles que só tiveram acesso à aprendizagem veiculada pelas obrigações de um ofício ou a que thes foi transmitida pelos contatos sociais com seus semelhantes (BOURDIEU, p. 221, 2007).

Bourdieu (2007) traz a importância da educação escolar para os sujeitos que vivem em sociedade. Nessa perspectiva, o sistema de ensino traz para a realidade escolar os conhecimentos legítimos e reorienta os saberes do senso comum, as informações, a saberes científicos capazes de proporcionar qualidade às vivências dos sujeitos que passaram pela experiência do processo de ensino aprendizagem escolar. Podemos presumir que a trajetória de vida desses sujeitos terá muito mais capacitações do que restrições nas relações com os diversos espaços sociais.

Os termos habitus e "Ser Mais" estão intrinsicamente relacionados a ser oprimido ou opressor segundo as vivências e experiências nas relações sociais. O processo de mudança do sujeito, de reeducação constante, faz parte da ação consciente de se libertar da condição em que se encontra. Assim, o habitus forma-se e transforma. Para Freire (2013, p. 105), "a busca pela [...] autonomia vai se construindo na experiência de várias, inúmeras decisões que vão sendo tomadas. [...] enquanto amadurecimento do ser para si, é preciso, é vir a ser. Não ocorre em data marcada". Durante a trajetória de vida, os sujeitos constroem, reconstroem e transformam suas vidas por meio de suas relações com os campos e com o outro.

Freire (1980), em seu livro Pedagogia do Oprimido, trouxe algumas contribuições com relação à busca pela autonomia, humanização, libertação, superação da opressão pelos oprimidos e opressores, na busca do Ser Mais. Para Freire (1980), só haverá mudanças na posição social, cultural e política do sujeito nos campos de convivência, percebendo-se como ser inconcluso. Nesse processo, 
esta busca do Ser Mais, porém, não pode realizar-se no isolamento, no individualismo, mas na comunhão, na solidariedade dos existentes, daí que seja impossível dar-se nas relações antagônicas entre opressores e oprimidos (FREIRE, 1980, p. 86).

Como Freire (1980) apresenta, o homem é um ser inconcluso e, na consciência de sua inconclusão, está em busca constante de Ser Mais. Nas relações sociais, o diálogo tem papel importante na percepção da inconclusão, "[...] a inserção do sujeito inacabado num permanente processo social de busca (FREIRE, 2013, p. 54). Para Freire (2013), o diálogo é condição para leitura e interpretação do mundo. Assim,

O diálogo em que se vai desafiando o grupo popular a pensar sua história social como a experiência igualmente social de seus membros vai revelando a necessidade de superar certos saberes que, desnudos, vão mostrando sua "incompetência" para explicar fatos. (FREIRE, 2013, p. 79)

A percepção do inacabamento está nas relações dos sujeitos com os campos de convivência e com os outros sujeitos. Dito de outro modo, a autonomia, a consciência crítica, a participação ativa na sociedade, a dignidade de cada um, a emancipação social não são ações individuais, decorrem das relações sociais.

Nessa perspectiva, entende-se a busca pela emancipação social real ou ilusória por meio da escolarização. Sob esse ponto de vista, buscou-se em Adorno (1995) uma melhor compreensão acerca da emancipação social, de como esses sujeitos podem emancipar-se.

Adorno (1995) apresenta-nos a não emancipação, a emancipação ilusória e a importância da crítica constante sobre a sociedade, como dever da escola. Freire (1980) critica a forma como a escola "doutrina" os educandos segundo a necessidade dos "opressores". Entretanto, entende que a emancipação perpassa pela educação, que é necessária para a libertação, autorreflexão e autonomia dos sujeitos e para atuação crítica sobre o tempo e o espaço na sociedade em que vive. 
Para Freire, a emancipação é humana e social, ou seja, emancipação e a prática da liberdade individual só acontecem em sociedade. Portanto,

Não existe uma auto-emancipação pessoal? Não, não, não. Mesmo quando você se sente, individualmente, mais livre, se esse sentimento não é um sentimento social, se você não é capaz de usar sua liberdade recente para ajudar os outros a se libertarem através da transformação global da sociedade, então você só está exercitando uma atitude individualista no sentido do empowerment ou da liberdade. (FREIRE; SHOR, 2001, p. 135)

A emancipação social é dialética, é uma busca constante de participação social; a cada novo saber, podem ocorrer construções e reconstruções das individualidades, e estas podem fazer parte das relações sociais. A emancipação em Freire é uma conquista política, a luta dos sujeitos oprimidos por sua libertação decorre da luta constante de novos saberes e reflexões críticas sobre o mundo em que se vive.

Freire (1980) apresenta a importância do diálogo como meio para a libertação dos oprimidos e opressores. O diálogo verdadeiro liberta e transforma habitus. Desse modo,

A palavra viva é diálogo existencial. Expressa e elabora o mundo, em comunicação e colaboração. O diálogo autêntico - reconhecimento do outro e reconhecimento de si, no outro - é decisão e compromisso de colaborar na construção do mundo comum. Não há consciências vazias; por isto os homens não se humanizam, se não humanizando o mundo. (FREIRE, 1980, p. 15)

A participação ativa dos sujeitos em seus meios de convivência está no diálogo, na oralidade. Portanto, discutir e argumentar sobre os acontecimentos sociais com saberes legítimos, muitas vezes, só adquiridos no meio escolar, é importante para os sujeitos. O diálogo "autêntico" (FREIRE, 1980, p. 15) é essencial nesse processo, com sujeitos autônomos e participação ativa 
contextualizando os saberes adquiridos no ambiente escolar nos seus campos de vivência; o diálogo crítico é libertador.

Fica claro que a educação escolar não é necessariamente um fator de emancipação. Entretanto, para Freire (2006, p. 23),

[...] é preciso viver no meio das letras e não conhecer elas. [...] vão organizando uma forma cada vez mais justa de pensar, através da problematização de seu mundo, da análise crítica de sua prática, poderão atuar cada vez mais seguramente no mundo.

Assim sendo, a emancipação social entendida neste trabalho relaciona-se à capacidade reflexiva e autônoma dos sujeitos de participarem criticamente nos seus campos de convivência, na família, na escola e no trabalho. Entendemos que os sujeitos da EJA são atores sociais que agem segundo o seu habitus, no seu lugar nos campos de convivência. Nesse processo, há influência do capital cultural e social para a emancipação social dos sujeitos da EJA.

\section{EDUCAÇÃO POR IMAGENS: Futuro com escolarização para os sujeitos da EJA}

Após a discussão teórica acerca da trajetória de vida e emancipação social, analisamos os dados coletados por meio da atividade desenvolvida e organizada no formato de mosaico, conforme podemos observar no quadro 01. Nesse contexto, perceberam-se vestígios sobre os possíveis benefícios da escolarização para os sujeitos pesquisados. Com essas considerações, foram utilizadas as seguintes categorias de análise: desenvolvimento da pessoa humana, protagonismo, participação crítica na sociedade e mundo do trabalho, para buscarmos compreender a relação entre educação escolarizada e emancipação social. 
Quadro 1 - Benefícios da educação escolar para os sujeitos da EJA.

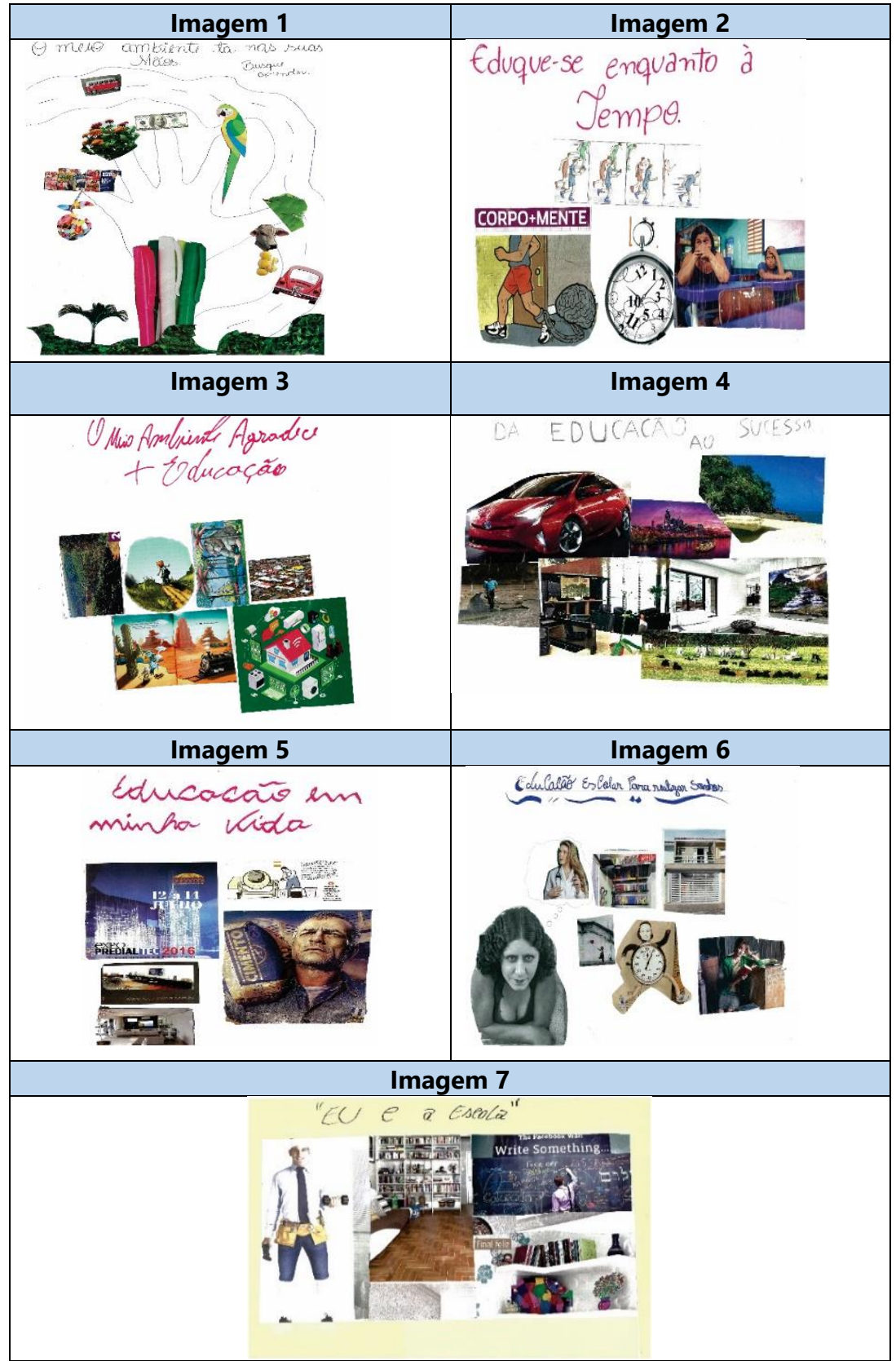

Fonte: Mosaicos elaborados pelos sujeitos para a pesquisa da dissertação (2019). 
Na imagem 1 (Quadro 1), com o título "O meio ambiente tá nas suas Mãos", pode-se observar que o sujeito escolheu as seguintes imagens e desenhos: uma mão e uma estrada, de caneta azul; uma floresta, de onde surge uma árvore estilizada; o braço é o tronco coberto por imagens de canetas; cada dedo representa uma área: revistas, remédios, vegetação, dinheiro, animais; na estrada, encontramos imagem de um carro, cabeças de gado e de frutas.

Nesse mosaico (imagem 1), é perceptível a importância da participação crítica na sociedade com relação às ações socioambientais. Percebe-se o protagonismo do sujeito por meio da percepção da importância da educação escolar para a vida das pessoas, nas áreas da saúde, trabalho, meio ambiente e informação. Nesse sentido, pode-se conjecturar o desenvolvimento da pessoa humana por meio da representação dos meios de comunicação e suas relações com o ambiente de sua convivência. Não foram possíveis análises com relação ao mundo do trabalho.

Na imagem 2 (Quadro 1), com o título "Eduque-se enquanto há tempo", observou-se uma tirinha que apresenta a sequência de uma corrida em que um dos participantes estava estudando e conseguiu vencê-la; um corpo com roupa de ginástica acorrentado a um cérebro; um cronômetro; em uma sala de aula, uma mãe com expressão de tristeza, quase chorando, e uma criança com expressão de aflição.

$\mathrm{Na}$ imagem 2, percebem-se as "angústias" do sujeito que elaborou o mosaico com relação à escolarização no tempo formal e à importância da família nesse processo, já é uma busca pelo desenvolvimento da pessoa humana. Em outra representação, notase o protagonismo desse sujeito ao reconhecer a importância da educação para conseguir melhorar de vida, e está matriculado na EJA. A participação crítica na sociedade está relacionada à busca por educação escolarizada para participar ativamente das relações sociais. O sujeito apresentou-nos a importância da escolarização no tempo formal e que, para almejar um futuro melhor, é preciso estudar.

Na imagem 3 (Quadro 1), com o título "O ambiente agradece + educação", descreve-se uma fazenda com plantação de café; uma estrada de terra e uma criança observando a paisagem; a caricatura 
de um animal com feições humanas e demonstrando tristeza e uma jangada chegando ao litoral; uma feira livre muito grande; a caricatura de um homem fazendo sinais de fumaça, uma locomotiva e dois trens modernos chegando; uma casa cercada por aparelhos de eletrodomésticos e eletrônicos.

No mosaico, imagem 3, o sujeito apresenta, por meio das colagens, a importância da educação para entender a inter-relação social, a busca da participação crítica na sociedade, a relação entre campo e cidade, a modernização dos meios de transporte e o desenvolvimento tecnológico. O protagonismo está na busca por conhecimento por meio da educação escolarizada, e, nesse processo, este sujeito reconhece-se como inconcluso e em busca pelo desenvolvimento da pessoa humana.

$\mathrm{Na}$ imagem 4 (Quadro 1), "Da educação ao sucesso", observou-se carro moderno; cidade grande próximo ao mar; praia deserta; homem fazendo exercício em estrada deserta; uma sala de escritório com dois ambientes; uma sala de estar com uma TV muito grande; uma fazenda com muitas cabeças de gado.

O mosaico da imagem 4 foi elaborado pelo sujeito a fim de apresentar os benefícios financeiros que a educação escolar pode proporcionar. Percebe-se o protagonismo do sujeito no momento em que busca por qualificação, a participação crítica na sociedade e no mundo do trabalho por perceber a importância da educação para a sociedade, nos campos laboral e social. A construção e reconstrução do seu habitus, desenvolvimento da pessoa humana, estão relacionadas às suas necessidades de uma vida melhor, com as benesses da sociedade contemporânea.

Na imagem 5 (Quadro 1), com o título “Educação em minha vida", há uma projeção da planta de três edifícios; uma sala ampla com móveis modernos; uma sala de TV e jantar com móveis; um homem fazendo a massa de cimento; um homem carregando um saco de cimento.

No mosaico, imagem 5, é notória a importância da escolarização para a vida do sujeito com relação à participação crítica no mundo do trabalho e na sociedade, com a melhoria da qualidade de vida. O ser protagonista está em buscar concluir o Ensino Médio para atender as necessidades do mundo contemporâneo. O habitus 
desse sujeito, desenvolvimento da pessoa humana, está relacionado às vivências e experiências no intuito da melhoria da qualidade de vida.

Na imagem 6 (Quadro 1), com o título "Educação Escolar para realizar sonhos", podem-se descrever: uma mulher pensando em ser médica; estante de livros em um espaço pequeno; uma criança que deixou o balão, em forma de coração, voar; a caricatura de uma mulher e um cronômetro; a frente de uma casa de andar; uma mulher sentada em uma caixa lendo um livro, espaço contendo muitas caixas.

$\mathrm{Na}$ imagem 6, o sujeito inseriu imagens que demonstram a importância da educação escolar para alcançar seus sonhos, o Ser Mais, o exercício da imaginação, das emoções, a razão de desenvolver-se como pessoa humana. O protagonismo está em buscar completar um ciclo de vida, a escolarização da educação básica, e galgar novos sonhos. O tempo, também, faz parte das inquietações desse sujeito; a participação crítica na sociedade e no mundo do trabalho só será possível com a busca por qualificação profissional na área que deseja seguir.

Na imagem 7 (Quadro 1), com o título "Eu e a escola", observaram-se: um homem com uma vestimenta representando várias profissões: jogador de futebol, eletricista, cozinheiro; informática; uma sala com um sofá e uma estante grande de livros; uma sala de aula e um professor escrevendo no quadro negro; uma estante com livros e objetos de arte.

No mosaico, imagem 7, o sujeito buscou apresentar a importância da escolarização para sua formação profissional, desenvolvimento da pessoa humana, para a sociedade em que vivemos e para o mundo do trabalho. Foi perceptível a relação entre escolarização e participação no mundo do trabalho. O protagonismo está relacionado à matrícula e à participação das atividades desenvolvidas no colégio onde esta pesquisa foi realizada.

Os sujeitos têm a visão de que a escola é o lugar dos saberes necessários para melhorar a sua vida, com relação à certificação e a conhecimentos importantes para as relações sociais. Há uma consciência crítico-reflexiva no intuito de participar nos seus campos de convivência. Entretanto, é perceptível que os sujeitos almejam na educação escolar os benefícios de ordem econômica e/ou social, uma 
vida melhor. Logo, os sujeitos buscam por bens e serviços que a sociedade pode oferecer, um trabalho/emprego melhor e um bom salário, com poder de compra de bens que estão disponíveis no mercado.

\section{CONSIDERAÇÕES FINAIS}

A relação entre habitus e Ser Mais está diretamente ligada às relações sociais, econômicas e políticas desenvolvidas na trajetória de vida dos sujeitos. Com esta pesquisa, percebeu-se a importância da escolarização para a vida dos sujeitos da EJA, como seres inconclusos e em busca da autonomia, consciência crítica e participativa nos campos de sua convivência, tanto familiar quanto laboral e na escola.

Os sujeitos que se encontram matriculados nas turmas da Educação de Jovens e Adultos são o resultado das relações culturais, materiais e simbólicas com o meio, ou seja, nos campos de convivência. Nesse movimento dialético, é formado o habitus de cada um.

$\mathrm{Na}$ atividade de construção do mosaico, percebemos a diversidade de interesses e necessidades dos sujeitos com relação à busca pela escolarização. A importância da educação escolar na Trajetória de Vida dos Sujeitos da EJA acontece de forma diferenciada; essa realidade ocorre em função da diversidade de vivências com relação à idade, cultura, valores e saberes adquiridos dos sujeitos, pois estes têm objetivos diferentes com relação à conclusão do Ensino Médio na EJA.

Percebemos que os sujeitos voltaram à escola em busca da certificação escolar para o mundo do trabalho e, para além disso, participarem ativamente nos seus campos de convivência. Os sujeitos têm a visão de que a escola é o lugar dos saberes necessários e capazes de melhorar suas vidas, oportunizando-Ihes uma consciência crítico-reflexiva e autonomia intelectual para compreender o que está acontecendo em Vitória da Conquista, na Bahia, no Brasil e no mundo e, assim, atuar nos seus campos de convivência.

O processo de escolarização é importante para os sujeitos pesquisados, mas em níveis e necessidades diferentes. A educação 
que ocorre na escola é fonte de informações em várias áreas e capaz de melhorar a vida dos sujeitos.

Percebemos que eles sentem a necessidade de melhorar a sua relação com seus campos de convivência, na família, com amigos, no trabalho e na escola. Contudo, vale ressaltar que esses sujeitos trazem para a sala de aula vivências e informações do senso comum que precisam ser sistematizadas pelo processo de ensino aprendizagem escolar; além disso, outros conhecimentos são essenciais para que possam participar crítica e ativamente do meio social em que vivem.

Os sujeitos atribuem valor para o processo de escolarização; essa relação foi perceptível por meio das imagens inseridas na atividade. Há vários motivos para o fato de que a educação escolar é importante para suas vidas, como, por exemplo, a busca por um emprego melhor, as exigências do mercado, aquisição de produtos disponíveis na nossa sociedade, um futuro melhor e a possibilidade de participar criticamente das relações sociais. Portanto, podemos perceber a busca por uma consciência crítico-reflexiva e pela autonomia intelectual a fim de atuar em seus campos de convivência. Com relação aos motivos que os conduziram de volta à escola, está a busca de certificação para o mundo do trabalho e, consequentemente, uma atuação de forma crítica no meio em que vivem.

\section{REFERÊNCIAS}

ABBAGNANO, Nicola. Dicionário de filosofia. São Paulo: Martins Fontes, 2007.

ADORNO, T. W. Educação e Emancipação. Trad. Wolfgang Leo Maar. Rio de Janeiro: Paz e Terra, 1995.

ARROYO, Miguel González. Passageiros da Noite: do trabalho para a EJA. Petrópolis, RJ: Vozes, 2017

BOURDIEU, Pierre. A economia das trocas simbólicas. 8. ed. São Paulo: Perspectiva, 2007.

BOURDIEU, Pierre. O poder simbólico. Rio de Janeiro: Bertrand Brasil, 1989. 
BOURDIEU, Pierre. Razões práticas: sobre a teoria da ação. 11. ed. Campinas, SP: Papirus, 2011.

FREIRE, Paulo. Pedagogia da Autonomia: saberes necessários à prática educativa. 44. ed. Rio de Janeiro: Paz e Terra, 2013.

FREIRE, Paulo. Pedagogia do Oprimido. 8. Ed. Rio de Janeiro: Paz e Terra, 1980.

FREIRE, Paulo. Ação cultural para a liberdade e outros escritos. 11. ed. Paz e Terra; 2006.

FREIRE, Paulo; SHOR, Ira. Medo e ousadia: o cotidiano do professor. 9. ed. Rio de Janeiro: Paz e Terra, 2001.

MICELI, Sergio. A Força do Sentido. In: BOURDIEU, Pierre. A economia das trocas simbólicas. $8^{a}$ ed. São Paulo: Perspectiva, 2007.

SILVA, Adriana de Mello Amorim Novais. Trajetória de vida dos sujeitos da EJA e o papel dos saberes geográficos para a emancipação social. 2020. 220f. Dissertação (Mestrado em Educação) - Programa de Pós-Graduação em Educação, Universidade Estadual do Sudoeste da Bahia, Vitoria da Conquista, Bahia, 2020.

Submetido em: Julho/ 2021.

Aceito em: Agosto/ 2021. 